\title{
DESIGN E EDUCAÇÃO DE SURDOS: projeto de livro traduzido do Português para Libras
}

\author{
Laíse Miolo de Moraes \\ Instituto Federal de Santa Catarina - Campus Palhoça Bilíngue \\ laise.moraes@ifsc.edu.br
}

\begin{abstract}
Resumo: O Instituto Federal de Santa Catarina - Campus Palhoça Bilíngue (Libras-Português) tem por missão a educação tecnológica orientada principalmente ao público surdo. Dentre muitas lacunas inerentes a uma área em construção, verifica-se a falta de materiais didáticos específicos para o público, usuário da Língua Brasileira de Sinais, como um dos maiores problemas. Assim, o objetivo deste trabalho foi desenvolver um projeto de Livro Digital, a partir da tradução de um livro técnico da área do Design, de português para Libras. Foi escolhido um tópico do livro "Novo Fundamentos do Design", com liberação prévia da editora, para a uma tradução piloto e um layout do projeto gráfico. A metodologia utilizada relaciona a demanda de tradução/interpretação com o Design, nas seguintes fases: Análise do Problema, Conceituação, Geração de Alternativas, Produção e Avaliação. Os resultados apontam para a contribuição da linguagem visual do Design aliada ao processo de tradução da língua oral-escrita para a língua viso-espacial. No projeto de Design, desenvolveram-se ilustrações, imagens e grafismos aliados ao conteúdo dos vídeos em Libras, o que proporcionou o enriquecimento da tradução, organização da leitura e familiarização do usuário surdo com a interface didática.
\end{abstract}

Palavras-chave: Design, Acessibilidade, Educação de Surdos, Língua de Sinais, Material didático, Design e Educação.

\section{INTRODUÇÃO}

O Instituto Federal de Santa Catarina - Campus Palhoça Bilíngue (LibrasPortuguês) tem como vocação a educação profissional de surdos; e, para tanto, converge esforços para efetivar uma proposta educacional bilíngue, no ensino presencial e à distância. Pelo menos em sua dimensão linguística, a educação para pessoas surdas está regulamentada pelo Decreto 5.626 de 2005, que garante a Língua Brasileira de Sinais e o Português na sua a modalidade escrita, como línguas de instrução durante todo o processo educativo.

No entanto, o ensino bilíngue não se sustenta apenas com o processo de tradução-interpretação, na medida em que envolve duas línguas de modalidades 
diferentes: o Português, na forma oral-auditiva e a Libras, no modo visual-espacial. São necessários materiais didáticos e objetos de aprendizagem específicos para os alunos surdos, usuários da Libras como primeira língua e do português na modalidade escrita como segunda língua. Respeitando-se sua cultura e língua materna, e sua relação histórica de exclusão do sistema de ensino por conta da sobreposição do português como língua de instrução.

Nesse sentido, a carência de materiais didáticos é grande, quase toda bibliografia de disciplinas técnicas são em português e os estudantes só contam com a exposição da aula traduzida, sem a oportunidade de revisar o conteúdo e estudar a partir de materiais didáticos produzidos na sua língua.

A visualidade, característica fundamental da cultura e identidade surdas, e a Libras, muitas vezes não são exploradas pelos materiais, permanecendo arraigados no tradicional paradigma do texto escrito (QUADROS, 2008). A dicotomia existente entre as linguagens verbal e visual, com amplo domínio secular da primeira, é para Bonsiepe (2011) um dos enfrentamentos do Design. Atualmente estuda-se o papel da visualidade para a distribuição e assimilação de saberes e também para a compreensão de assuntos complexos, a fim de elevar o status do uso de imagens nas ciências. Para Bonsiepe (2011), a tendência geral à visualização tem profundas consequências intelectuais e práticas para as ciências humanas, ciências exatas, sociais e todas as formas de ensino. Ao contrário de um papel secundário de elaborar ilustrações para apoiar o domínio do texto, a visualidade avança para o domínio próprio.

Nesse contexto, a tradução e a elaboração de objetos de aprendizagem, sejam materiais didáticos complementares ou bibliografias básicas, orientados pela visualidade, são urgentes para efetivar a educação bilíngue. A demanda do Design é o desenvolvimento dos projetos gráficos de materiais didáticos, imagens e ilustrações que se associem à tradução para as línguas viso-espaciais.

Desse modo, este estudo vai ao encontro da interface do Design com a Educação, por meio de seus processos e projetos de objetos de aprendizagem. 0 objetivo foi desenvolver um projeto piloto de Livro Digital, a partir de um livro didático impresso "Novos Fundamentos do Design", das autoras Ellen Lupton e Jennifer Cole Phillips. Foi traduzido para o português no Brasil pela Editora Cosac Naif, a qual autorizou a tradução para Libras. Este projeto contempla o design gráfico do livro digital, a partir da tradução de um capítulo do livro. Para assim, delinear as necessidades de trabalho juntamente com os intérpretes, e futuramente poder fazer a tradução por completo, com uma equipe multidisciplinar.

\section{DESIGN DA INFORMAÇÃO, VISUALIDADE E LÍNGUA DE SINAIS}

Na década de 1960, foi conferido a Libras o status de língua, e, conforme estudos lingüísticos mostram, as línguas orais e as línguas de sinais são similares em seu nível estrutural, formadas a partir de unidades simples que, combinadas, formam unidades mais complexas (Gesser, 2009). A diferença dessas línguas é quanto a forma e ao canal de comunicação em que cada língua se estrutura (visual-gestual $X$ vocalauditivo). Assim, a língua de sinais tem uma gramática própria e se apresentam estruturada em todos os níveis, como as línguas orais: fonológico, morfológico, sintático e semântico. 
As línguas de sinais são caracterizadas pela combinação de movimentos corporais, elas "são denominadas línguas de modalidade gestual-visual (ou espaçovisual), pois a informação linguística é recebida pelos olhos e produzidas pelas mãos" (QUADROS \& KARNOPP, 2004). Esta característica tem apresentado desafios para o seu registro. Quatro formas são mais difundidas: o signwriting, a ilustração, a fotografia, e o vídeo. De acordo com Silva (2009) "O sistema de escrita Signwriting SW é um sistema complexo e adaptável às gramáticas das línguas de sinais. No Brasil, é utilizado em algumas escolas de surdos e classes bilíngues na disciplina Língua de Sinais". A ilustração e a fotografia são recursos estáticos e, portanto, seus principais desafios recaem sobre o como representar as diferentes posições e configurações das mãos em momentos distintos. O vídeo, por sua vez, consegue suplantar esta dificuldade, permitindo uma reprodução mais fidedigna dos movimentos realizados na sinalização. Com a informática e a democratização das tecnologias digitais o vídeo consolidou-se como uma ferramenta transformadora na qualidade de vida $e$ comunicação da comunidade surda, promovendo a interação, educação e desenvolvimento da própria língua.

Nesse contexto, a discussão sobre o modo de registro das línguas de sinais vai ao encontro de uma demanda problemática do Design: existe muitas vezes a necessidade de usar a linguagem verbal para expressar conteúdos visuais; isso porque, ainda vive-se em uma cultura de separação entre as linguagens verbal e visual (lida, 2009). Complementando, Bonsiepe (2011) avalia que as novas tecnologias da informática irão unir a linguagem verbal com a imagem, visto que:

"a ciência da imagem está se consolidando e o design tem explorado o potencial da visualidade e confirmando sua qualidade epistêmica. As novas técnicas digitais de visualização acabarão com o domínio do texto, tão fortemente arraigado na tradição ocidental. Para essa nova área de atividades, determinada pelas técnicas digitais, usa-se 0 termo 'design da informação'” (BONSIEPE, 2011, p. 40).

A área do design de informação aplica conhecimentos da psicologia cognitiva, lingüística, teoria da percepção, teoria da aprendizagem, semiótica e do design visual (Bonsiepe, 2011). Desse modo, em um processo de tradução de um projeto de material didático do português para Libras, o trabalho do designer está ligado à forma de representação dos conhecimentos na mediação entre a fonte e o receptor. Essa mediação ocorre por meio de interfaces em que o conhecimento pode ser percebido e assimilado pelo usuário.

Ainda, para Bonsiepe (2011), a comunicação eficiente depende do uso de recursos que contêm necessariamente um componente estético. Nos recursos lingüísticos, isso pertence ao domínio da retórica, que tem a ver com a preparação estética do discurso, evitando-se o tédio. Nesse sentido, a tarefa do design de informação consiste em reduzir a complexidade cognitiva, produzir clareza e, dessa maneira, contribuir para uma melhor compreensão dos conteúdos. Isso se consegue mediante uma aplicação equilibrada dos recursos audiovisuais (BONSIEPE, 2009, p. 88).

Assim, o trabalho para a produção de materiais didáticos bilíngües ou para um processo de tradução entre línguas formalmente distintas requer-se trabalho em equipe: designers, animadores, tradutores, intérpretes, professores. Nesse grupo, a 
demanda do designer se caracteriza pelas duas constantes: a preocupação com as características do usuário e o cuidado com a qualidade formal-estética. Sem que uma sobressaia à outra ou que seja interpretado de maneira sobreposta.

\subsection{Metodologia}

A pesquisa relaciona duas grandes áreas do conhecimento, a saber, a Tradução/Interpretação e o Design. No entanto, o foco principal deste trabalho são as contribuições do design na tradução e no desenvolvimento do layout livro digital. Assim, a metodologia utilizada é baseada no processo de design de Löbach (2001). Para o autor, o designer deve solucionar os problemas de projetos, recolhendo informações e dados sobre o problema, relacionando-os com sua experiência e conhecimento, a fim de criar alternativas para a solução do problema (desenhos). Essas são avaliadas conforme critérios estabelecidos para desenvolver-se a alternativa mais adequada.

Desse modo, esta pesquisa segue as seguintes fases metodológicas, que relacionam o trabalho do design com a demanda da tradução/interpretação:

1) Análise do Problema;

2) Conceituação;

3) Geração de Alternativas;

4) Produção;

5) Avaliação.

A Análise do Problema compreende o entendimento sobre os assuntos relacionados na pesquisa e um levantamento de dados. Na Conceituação, definem-se as ideias conceituais do produto, bem como, a sistematização da tradução, que influenciará no design do produto. Na geração de alternativas são feitos os desenhos do produto (layouts). Na fase de produção, seleciona-se e desenvolve-se a alternativa de desenho final do produto. A avaliação é feita com base em critérios do design visual e também compreende a observação do uso do produto pelo usuário.

\section{CONCLUSÃO}

Na primeira etapa do trabalho, na Análise do Problema, foi feita uma revisão bibliográfica sobre os aspectos da cultura surda, da língua de sinais, algumas considerações acerca da tradução. No âmbito do Design investigou-se o papel da visualidade e as possibilidades de articular linguagens visuais com a língua de sinais. Foi feito um levantamento de materiais didáticos disponíveis em Libras-Português. A análise desses materiais mostra que existe a preocupação com a disponibilização dos conhecimentos na língua de sinais e português, mas apresenta muitos problemas de leitura e pouca atenção ao design gráfico. Abaixo, a Fig. 1 apresenta a interface de um DVD de apoio ao livro didático da disciplina de História da 4a série, da editora Arara Azul. 


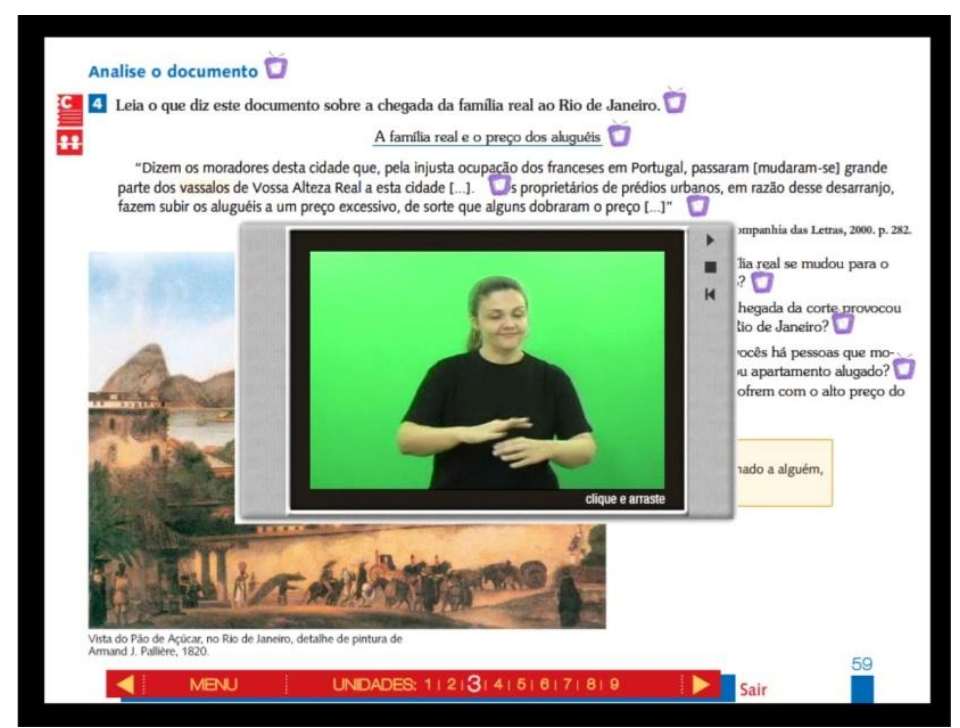

Figura 1 - Interface de DVD. DVD Didático, Editora Arara Azul.

É possível observar que a linguagem visual e o design gráfico foram pouco explorados nessa interface. $O$ texto em português possui linhas muito compridas de leitura e há pouco estudo de relação e hierarquia entre imagem, texto e janela de tradução, o que confunde a atenção do usuário. Conforme Krusser (2012), colunas de textos mais estreitas favorecem a leitura mais rápida e a largura da linha para a leitura de um texto longo não pode ser muito grande. Essa medida deve estar de acordo com o espaçamento entre linhas, evitando que na leitura, ao passar de uma linha para outra se pule uma linha. É visto também que a Libras é colocada em segundo plano, quando se usa a janela de tradução como opção para o texto em português.

Após o levantamento de dados, iniciou-se o processo Conceituação da ideia do Livro Digital. Definiu-se por utilizar a semântica do livro impresso, ou seja, com o folhear das páginas. Essa ideia reforça a possibilidade dos alunos surdos também poderem ter acesso a "livros" para estudar na sua língua - a Libras. Nessa fase iniciouse o trabalho junto à intérprete e bolsista de tradução, conforme as seguintes fases:

1. Leitura e discussão do texto a ser traduzido: o designer discute com o intérprete as questões técnicas a serem traduzidas e os termos novos.

2. Adaptação do texto para a tradução para Libras.

3. Planejamento da Tradução: $O$ intérprete planeja juntamente com um professor surdo, são verificadas as palavras que não possuem sinal na língua.

4. Planejamento da Tradução visual: $O$ designer precisa entender junto ao interprete o que é necessário em termos de imagens, desenhos ou animações que complementem a tradução.

Nessa fase, o que demandou mais trabalho foi pensar a tradução visual e como o texto em Libras seria colocado no desenho do livro. Por exemplo, se a intérprete está explicando sobre certa figura ela precisa apontar para a direção desta imagem. Assim, foi necessário fazer escolhas sobre o que seria necessário explicar linguisticamente e o que já poderia ser contemplado somente com as figuras do livro; pois, conforme Krusser (2012) ao transpor um conteúdo para a língua de sinais é necessário considerar que o leitor surdo precisa optar em olhar para o intérprete ou para o que é mostrado.

Em seguida iniciou-se a Geração de Alternativas, com a produção dos desenhos do livro digital. As discussões orientaram-se no sentido de fazer um layout que fosse 
ao encontro das expectativas do estudante surdo, privilegiando a sua língua e cultura. Abaixo as figuras apresentam algumas das opções de layout desenvolvidas.

\title{
Cores
}

\begin{abstract}
A simetria pode ser da esquerda para a direita, de cima para baixo, ou ambas. Muitos organismos naturais têm forma simétrica. mesmo peso para braços e pernas ajuda a garantir a mobilidade estável de uma criatura; uma árvore desenvolve uma distribuição equivalente de peso em torno de seu centro a

fim de manter-se ereta; e os braços de uma estrela-do-mar irradiam-se a partir do centro.
\end{abstract}
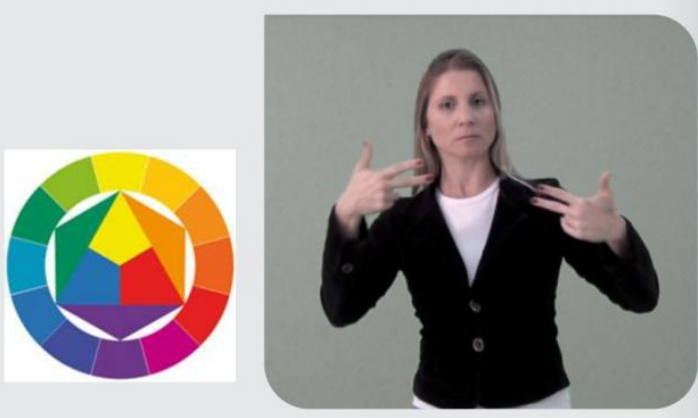

마무

Figura 2 - Opção de layout no 1. Desenvolvido pelo autor, com base na pesquisa realizada.

\section{Simetria e Assimetria}

A simetria pode ser da esquerda para a

direita, de cima para baixo, ou ambas. Muitos organismos naturais têm forma simétrica. $\mathrm{O}$ mesmo peso para braços e pernas ajuda a garantir a mobilidade estável de uma criatura; uma árvore desenvolve uma distribuição equivalente de peso em torno de seu centro a fim de manter-se ereta; e os braços de uma estrela-do-mar irradiam-se a partir do centro.

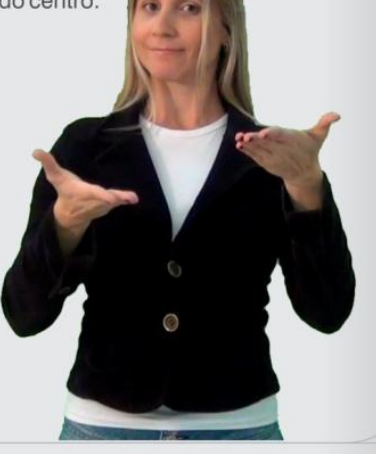

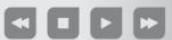

Figura 3 - Opção de layout no 2. Desenvolvido pelo autor, com base na pesquisa realizada. 


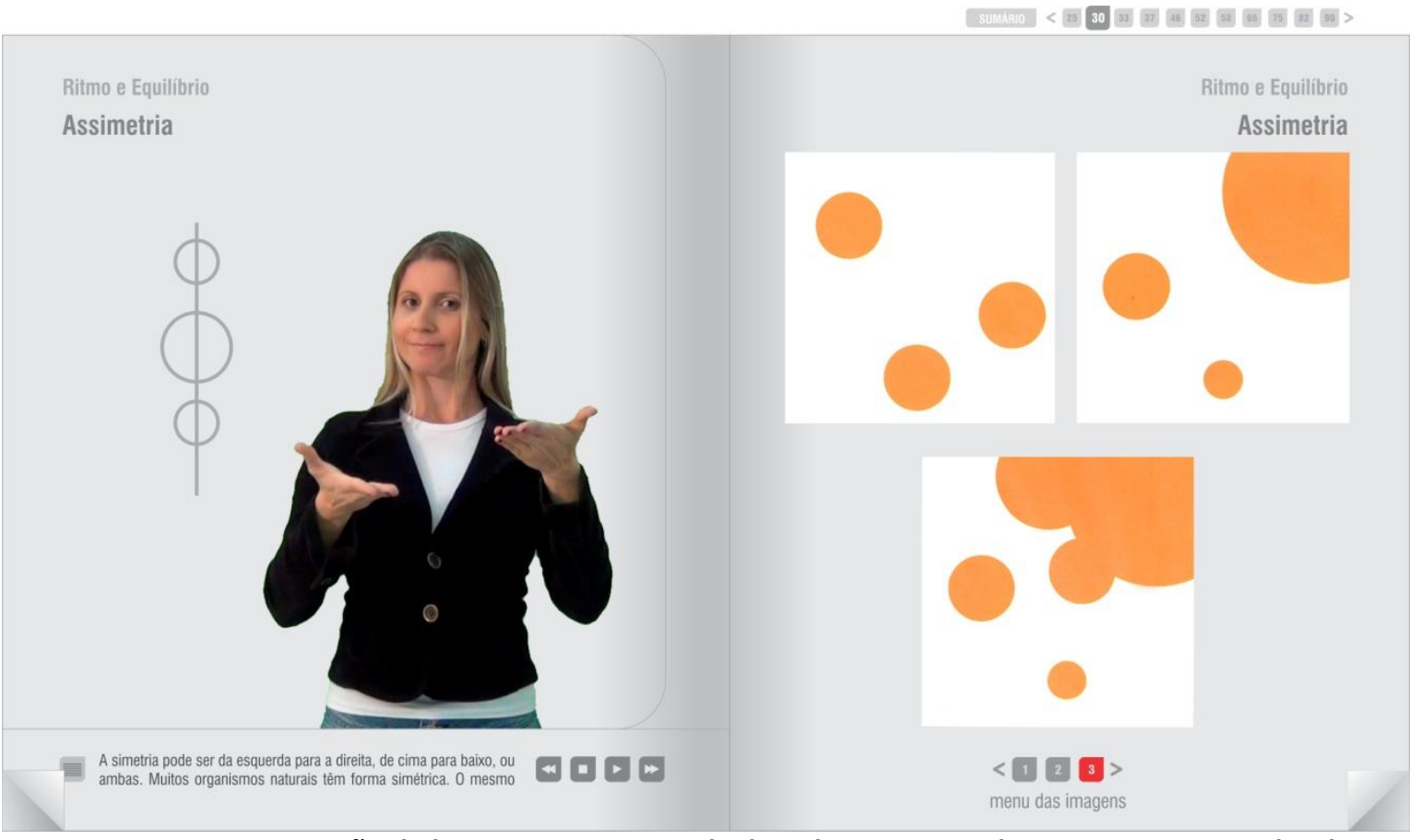

Figura 4 - Opção de layout no 2. Desenvolvido pelo autor, com base na pesquisa realizada.

Na Figura 2, pensava-se em usar o vídeo de tradução dentro de um quadro, como de costume; o texto em português ao lado e possivelmente algumas imagens do livro. Já na Figura 3, optou-se por retirar a intérprete do quadro de tradução, utilizando o vídeo com o fundo recortado. O que ficou bem mais interessante e legível para o surdo, pois a maioria das traduções disponíveis em televisão, por exemplo, são feitas em quadros pequenos no canto da tela, desfavorecendo a língua e o entendimento.

Conforme Reichert (2012), assim como os ouvintes em relação às línguas orais, os surdos, com suas línguas de sinais, também têm na língua a garantia de pertencimento a uma comunidade. Desse modo, ficou claro que seria necessário trazer a língua de sinais visualmente para o patamar de primeira língua, de maneira que esta ganhasse espaço na página do livro. Assim, optou-se por colocar a intérprete na página esquerda do livro, com o português apenas como opção em legenda.

A organização das imagens teve que ser redefinida do livro impresso para o digital, por conta das questões de tradução. Visualizou-se a necessidade de apresentar somente as imagens que se está sinalizando, para não confundir o leitor. Assim, conteúdos que ocupam uma página no livro impresso tornaram-se, quatro páginas do livro no digital, por exemplo.

A Figura 4 representa um dos layouts finais do livro. Optou-se por utilizar o conteúdo em Língua de Sinais na página esquerda do livro, obedecendo a ordem ocidental de leitura. E as imagens figurativas à direita. Para o controle do vídeo em Libras foi feito um menu de botões utilizados em interfaces digitais; e para demarcar a passagem das figuras do livro também feito um menu que contabiliza a passagem das imagens.

A fase de Produção iniciou com o tratamento das imagens do livro. Logo após, as filmagens no estúdio dos conteúdos em Libras e a edição dos vídeos. Como apoio ao conteúdo em língua de sinais foram desenvolvidos alguns desenhos e grafismos animados. Por fim, o layout foi finalizado em um programa gráfico de animação. A questão de maior discussão nessa fase foi entender juntamente com intérprete ou um 
surdo, quais as partes do conteúdo em Libras seriam interessantes de ter um apoio de desenho e imagem.

Por fim, foi feita uma avaliação qualitativa do material, a partir da observação de uso do livro por cinco alunos surdos, que responderam algumas questões. As perguntas orientaram-se a compreensão do conteúdo, possíveis sobreposições de texto e imagem e sugestões para melhoria. Abaixo, as questões e o número de respostas:

a) A intérprete faz relação com os exemplos de imagens do livro?

( 4 ) Sim, muito. ( 1 ) Sim, mas poderia melhorar. ( ) Muito pouco. ( ) Não

b) A visualidade é atrativa e vai ao encontro da cultura surda?

( 3 ) Sim, muito. ( 2 ) Sim, mas poderia melhorar. ( ) Muito pouco. ( ) Não

c) O livro digital satisfaz a necessidade de apoio dos estudos?

( 5 ) Sim, muito. ( ) Sim, mas poderia melhorar. ( ) Muito pouco. ( ) Não

Finalmente, pesquisa em design, orientada a materiais didáticos específicos para a educação de surdos ainda está iniciando no país. Muitos dos estudos de design sobre acessibilidade, no âmbito ergonômico encaram a surdez como deficiência e não como diferença cultural, indo de encontro ao que a comunidade surda aceita e defende. Assim, os materiais educacionais desta área apresentam dificuldades de avançar em seus projetos e também em alcançar seu público destinatário.

Portanto, para o design de fato contribuir com a educação bilíngue, coerente com as especificidades do surdo, são necessários materiais culturalmente adequados, e isso inicia com o respeito à diferença linguística desta comunidade, respeitando-se o uso da Língua Brasileira de Sinais.

Assim, mostra-se que a função do design não é apenas estética, aquela de fazer o design bonito de um livro. Pois, a língua de sinais apresentada em vídeo enriquece muito com o apoio visual de desenhos, grafismos e animações, associados à interpretação como apoio à língua. A linguagem visual pode participar ativamente do conteúdo e, em especial contribui para a eficiência da tradução de temas complexos, uma vez que complementa, mostra, relaciona e direciona o olhar do usuário.

Grande parte deste trabalho foi de relação com o tradutor/intérprete, procurando entender quais as adequações necessárias do texto em português para Libras e qual a demanda de imagens para apoiar o conteúdo. Conclui-se que ao mesmo tempo é importante relacionar imagens à língua de sinais, é preciso ter cuidado para uma informação não se sobrepor à outra.

O Design do livro digital com a semântica de uso do livro impresso: virar as páginas, possuir índice e numeração de páginas, procurou aproximar o público surdo desta mídia, sabendo-se que é histórico o afastamento do aluno surdo dos livros e da língua portuguesa. É interessante que os usuários se identifiquem com as interfaces, criando identidade e promovendo a sensação de pertencimento e familiaridade com o objeto. 
A adaptação aos diferentes desejos e necessidades dos usuários é um processo permanente de comunicação, onde se identifica novas demandas e possibilidades de melhorias. O layout do Livro Digital apresentado é uma possibilidade de modelo para a tradução de materiais didáticos impressos em língua escrita para o meio digital em língua gestual. Onde se delineou o método de trabalho entre designer $\mathrm{e}$ tradução/interpretação para traduções futuras em equipes multidisciplinares, contando com designers, tradutores, intérpretes, professores e usuários surdos, ilustradores e programadores.

\section{REFERÊNCIAS}

BONSIEPE, Gui. Design, Cultura e Sociedade. São Paulo: Blucher, 2011.

GESSER, Audrei. Libras? Que língua é essa? Crenças e preconceitos em torno da língua de sinais e da realidade surda. São Paulo: Parábola Editorial, 2009.

IIDA, Itiro in BONSIEPE, Gui. Design, Cultura e Sociedade. São Paulo: Blucher, 2011.

KRUSSER, Renata. Elementos de Design editorial na tradução didática Português/Libras. In: 10 SEPEI - Seminário de Pesquisa, Extensão e Inovação do Instituto Federal de Santa Catarina. Anais... - IFSC Palhoça-Bilíngue, 2012.

LACERDA, Cristina B. Intérprete de Libras em atuação na educação infantil e no ensino fundamental. Porto Alegre: Mediação/ FAPESP, 2009.

LÖBACH, Bernd. Desenvolvimento de Produtos Industriais. São Paulo: Blucher, 2001.

QUADROS, R. M. de. (org). Estudos Surdos III. Série pesquisas. Petrópolis, RJ: AraraAzul, 2008.

REICHERT, André Ribeiro. Intérpretes, Surdos e negociações culturais. In: PERLIN, Gladis; STUMPF, Marianne (org.). Um olhar sobre nós surdos: leituras contemporâneas. CRV, Curitiba, PR, 2012. 